\title{
Integrating Computing and Computational Thinking into K-12 STEM Learning
}

\author{
Shuchi Grover \\ (moderator) \\ Stanford University/ \\ Looking Glass Ventures \\ shuchig@cs.stanford.edu
}

\author{
Kathryn Fisler \\ Brown University \\ Dept of Computer Science \\ Providence, RI USA \\ kfisler@cs.brown.edu
}

\author{
Irene Lee \\ MIT STEP Lab \\ 700 Technology Square \\ Cambridge, MA 02139 \\ ialee@mit.edu
}

\author{
Aman Yadav \\ Michigan State University \\ 620 Farm Lane \\ East Lansing, MI 48824 \\ ayadav@msu.edu
}

\begin{abstract}
Policymakers believe that preparing all students from the earliest grades to high school for a new future of STEM+Computing $(\mathrm{STEM}+\mathrm{C})$ integration involves teaching them not only the science and math central to these areas, but also how computational thinking is integral to STEM disciplines. This panel brings together four researchers who focus on research and development of interdisciplinary approaches to the integration of computing within STEM teaching and learning for preK-12 students. They will share the most impactful, practical, and promising approaches to $S T E M+C$ integration, their pros and cons, challenges, and key insights to successful STEM $+C$ integration at all grade levels.
\end{abstract}

\section{SUMMARY}

Computation is considered the third pillar of the scientific method, along with theory and experimentation. The $21^{\text {st }}$ century is witnessing a steady rise of "Computational X" that acknowledges the integration of computing and computational thinking (CT) in disciplines (especially STEM domains) as a tool to drive innovation. Driven by these changing needs, K-12 education stakeholders are looking to teach computing and $\mathrm{CT}$ as foundational competencies for all students, and STEM subjects are seen to be a rich home for integration of computing. Denning's recent writings on CT have highlighted that computational science has been the shining example and best argument for $\mathrm{CT}$ as a valuable way of bringing CS and computers into non-CS disciplines. Efforts for integration received a fillip with CT listed as. a disciplinary practice in the Next Generation Science Standards (NGSS) [8]. Both, the NGSS and Common Core Mathematics Standards place a new emphasis on not only using models, but also creating models to critically interrogate phenomena and understand simplifying assumptions.

The productive integration of STEM and computing learning for children dates back to the 1980s. Papert's pioneering work in helping young children develop a 'mathematical way of thinking' through programming the LOGO turtle [9] and diSessa's

Permission to make digital or hard copies of part or all of this work for personal or classroom use is granted without fee provided that copies are not made or distributed for profit or commercial advantage and that copies bear this notice and the full citation on the first page. Copyrights for third-party components of this work must be honored. For all other uses, contact the Owner/Author.

SIGCSE '20, March 11-14, 2020, Portland, OR, USA

(C) 2020 Copyright is held by the owner/author(s).

ACM ISBN 978-1-4503-6793-6/20/03.

https://doi.org/10.1145/3328778.3366970 demonstrations of how 6th graders could model complex physics phenomena while programming in Boxer [1] stand as testimony to the rich possibilities of integrating STEM learning with computing that benefits learners in ways that cannot be achieved in nonintegrated contexts. This view of CT was operationalized into a framework of CT in STEM domains based on agent-based modeling research led by Uri Wilensky and his research lab [12]. A recent NSF-funded workshop organized by a core team of interdisciplinary experts (including panelists Lee and Grover), convened researchers and teachers who deliberated on what CT integration looks like from a disciplinary perspective in STEM classrooms. In their view, $\mathrm{CT}$ as a thinking skill or problem-solving approach in non-CS settings helps with- (1) better understanding of phenomena (including making predictions and understanding potential consequences of actions), (2) innovating with computational representations, (3) designing solutions that leverage computational power or tools, and (4) engaging in sense-making around data [7].

Several efforts in the U.S. (many of which have been funded by the NSF STEM+Computing program) are actively developing and examining new approaches and curricula for integrating computing into STEM classrooms through activities that help learners-in primary, middle, and high school levels-build both CT and domain knowledge and skills in the STEM subject. Some involve coding in introductory programming environments like Python, Racket, Snap!, and StarLogo, while others (especially at the younger grade levels) combine unplugged approaches with plugged ones. Regardless of the approach, they must all address challenges of transforming science and math learning in new and innovative ways. This panel will present these varied perspectives on integration, starting with an overview of why we should look for opportunities to integrate CT and computing in all STEM learning (Grover) followed by research on (a) the Bootstrap approach to integrating computing and data science (Fisler); (b) learning science through computational agent-based modeling (Lee); (c) integration of CT with math and science activities in elementary grades through unplugged activities; and (d) identifying fertile opportunities for integrating CT in PreK learners science and math activities in school and at home (Grover). This session will cover the gamut of CT integration across all grade levels of PreK-12 school education.

\section{PANEL STRUCTURE}

The panel will open with a brief overview by the moderator describing the session (5 mins). Panelists Fisler, Lee, Yadav, and Grover will be given 12 minutes each to present their respective approaches to STEM $+\mathrm{C}$ integration in high, middle, elementary 
and PreK grade levels. Following the presentation, the moderator will facilitate a Q\&A that will probe on-the-ground experience, tensions and challenges related to achieving learning goals in multiple domains (STEM domain and computing), teaching coding concurrently with domain-specific concepts and practices, teacher experiences and professional development, assessing integrated learning, and key takeaways for educators interested in integrating computing in other subjects.. Following that, the moderator will facilitate audience discussion. We anticipate questions about practical strategies, and discussion around what approaches are better suited to various K-12 levels and how to engage and involve STEM teachers who may be unfamiliar with $\mathrm{CT}$ and computing.

\section{SHUCHI GROVER (Moderator)}

I am a researcher specializing in K-12 CS education, computational thinking [2], and STEM+Computing integration I lead/co-lead several NSF-funded STEM $+\mathrm{C}$ projects at the pre-K, middle, and high school levels [4] that examine varied innovative and productive approaches to integration of CT in Math and Science learning. My experiences in integration of STEM+CT range from the use of computational modeling in science, to coding algorithms for algebraic and geometry reasoning, and leveraging synergies between CT and STEM concepts and practices to design young learners' preschool experiences with deeper, analytical, digital and unplugged activities that integrate elements of CT [3].

\section{KATHI FISLER}

I am co-founder of Bootstrap (https://www.bootstrapworld.org), a long-running project specializing in integrating computing and data science into existing K-12 classes (e.g., math, physics and social studies). Bootstrap uses functional programming to align computing concepts with topics and learning objectives in algebra, which in turn are used in physics. This programming style matches that of modern data-analysis platforms, which make substantial use of iterators and higher-order functions. Leveraging math concepts that teachers already need to cover raises teacher buy-in while still allowing students to work on substantial and interesting projects in game design, scientific simulations, and data analysis. It can also align the computing content with content standards and performance assessments $[10,11]$ in other disciplines, while reducing the overhead of teaching additional material.

\section{IRENE LEE}

I am founder/director of Project GUTS - Growing Up Thinking Scientifically (http://www.projectguts.org.), a middle school CT integration program focused on computer modeling and simulation of complex systems phenomena [6]. Project GUTS' CS in Science curriculum promotes a "learn to code" then "code to learn" trajectory. I believe the integration of CS in science should engage students in authentic computational science practices and support student agency by enabling customizations to models so students can test their own ideas about the generators of phenomenon. In addition to sharing examples from Project GUTS, I will also describe my work related to preparing teachers to integrate agent-based modeling tools like StarLogo Nova into classrooms [5].

\section{AMAN YADAV}

As a professor of education with a focus on educating in-service and pre-service teachers, I work to bring CT into K-12 classrooms, especially at the elementary level. Using unplugged CT approaches, university researchers, classroom teachers, and school curriculum consultants have come together to co-design lessons for teachers to integrate CT. I will share examples from our work with elementary teachers and how they have brought unplugged computational thinking within the context of their elementary classrooms using a CT toolkit [13]. In addition, I will discuss how unplugged approach provides teachers with an on ramp to plugged $\mathrm{CT}$ as they come to see the relevance of $\mathrm{CT}$ to their disciplinary learning goals.

\section{REFERENCES}

[1] DiSessa, A.A., 2001. Changing minds: Computers, learning, and literacy. MIT Press.

[2] Grover, S. and Pea, R., 2013. Computational thinking in K-12: A review of the state of the field. Educational researcher, 42(1), pp.3843.

[3] Grover, S., Dominguez, X., Kamdar, D., Vahey, P., Moorthy, S. Rafanan, K. and Gracely, S. 2019.. Integrating Computational Thinking in Informal and Formal Science and Math Activities for Preschool Learners. In Proceedings of the 50th ACM Technical Symposium on Computer Science Education (pp. 1257-1258). ACM.

[4] Grover, S., Hutchins, N., Biswas, G., Snyder, C., \& Emara, M. (2019). Examining synergistic learning of physics and computational thinking through collaborative problem solving in computational modeling. AERA, Toronto, $C A$.

[5] Hsiao, L., Lee, I., and Klopfer, E. 2019. Making sense of models: how teachers use agent-based modeling to advance mechanistic reasoning. British fournal of Ed. Technology 50(5): 2203-2216.

[6] Lee, I., Martin, F. Denner, J., Coulter, B., Allan, W., Erickson, J., Malyn-Smith, J., and Werner, L. 2011. Computational Thinking for Youth in Practice. ACM Inroads 2(1): 32-37.

[7] Malyn-Smith, J., Lee, I. A., Martin, F., Grover, S., Evans, M. A., \& Pillai, S. (2018). Developing a Framework for Computational Thinking from a Disciplinary Perspective. In Proceedings of the International Conference on Computational Thinking Education 2018. Hong Kong: The Education University of Hong Kong.

[8] NGSS Lead States (2013) Next generation science standards: for states, by states. The National Academies Press.

[9] Papert, S., 1972. Teaching children to be mathematicians versus teaching about mathematics. International Journal of mathematical ed. in science and technology, 3(3), pp.249-262.

[10] Schanzer, E., Fisler, K., Krishnamurthi, S., and Felleisen, M. 2015. Transferring Skills at Solving Word Problems from Computing to Algebra Through Bootstrap. Proceedings of the $46^{\text {th }}$ technical symposium on CS education (SIGCSE '15)

[11] Schanzer, E., Fisler, K., and Krishnamurthi, S. 2018. Assessing Bootstrap:Algebra Students on Scaffolded and Unscaffolded Word Problems. Proceedings of the $4^{\text {th }}$ technical symposium on Computer science education (SIGCSE '18).

[12] Weintrop, D., Beheshti, E., Horn, M., Orton, K., Jona, K., Trouille, L. and Wilensky, U., 2016. Defining computational thinking for mathematics and science classrooms. Fournal of Science Education and Technology, 25(1), pp.127-147.

[13] Yadav, A., Larimore, R., Rich, K., Schwarz, C. (2019). Integrating computational thinking in elementary classrooms: Introducing a toolkit to support teachers. In Proceedings of Society for Information Technology \& Teacher Education International Conference2019. Chesapeake, VA: AAC 